\title{
Sexual Dimorphism in Adult Human Mandible of North Indian Origin
}

\author{
Rahul Singh, Suniti R. Mishra*, Sushobhana, Jigyasa Passey, Pramod Kumar, \\ Shailendra Singh, Priyanka Sinha, Smrity Gupta \\ Department of Anatomy, G.S.V.M. Medical College, Kanpur, India \\ Email: drrahulsingh58749@gmail.com, ${ }^{*}$ dr.suniti@yahoo.co.in, sushobhana@gmail.com, \\ jigyasapassey@gmail.com, drpkumargsvm@gmail.com, shailendra.anatomy@gmail.com, \\ priyankasinha971@gmail.com, doctorsmrity@gmail.com
}

Received 19 June 2015; accepted 20 July 2015; published 23 July 2015

Copyright (C) 2015 by authors and Scientific Research Publishing Inc.

This work is licensed under the Creative Commons Attribution International License (CC BY). http://creativecommons.org/licenses/by/4.0/

c) (i) Open Access

\section{Abstract}

Background: In forensic science the identification of a human is based on three important factors: Age, Sex and Stature. Bones are an important tool for it and among human bones the pelvis and the skull are the most reliable source for sex determination. In the absence of complete pelvis, mandible becomes the important source for sex determination since mandible is the most durable and movable part of skull that can resist postmortem changes. The present study is conducted to assess the accuracy and role of few metric and morphological parameters in determination of the sex of dry adult human mandible of North Indian origin. Material \& Methods: The Study is conducted on 50 dry intact human adult mandibles of North Indian origin. The metric parameters i.e. bigonial breadth, bicondylar breadth are measured with a Vernier Calliper by two observers. Non-metric parameters being observed are the morphological features like gonion flaring, muscular markings and shape of angle of symphysis menti. Result \& Conclusion: It is concluded that bigonial breadth and bicondylar breadth exhibit the sexual dimorphism. Morphological Parameters: Gonion flaring, muscular markings and shape of angle of symphysis menti also demonstrate the sexual dimorphism. These parameters taken together may determine the sex of adult human mandibles. The present study shows that the mandible is an important tool in the determination of gender with high accuracy.

\section{Keywords}

Bicondylar Breadth, Bigonial Breadth, Gonion Flaring, Mandible, Sex Determination, Symphysis Menti

\footnotetext{
"Corresponding author.
}

How to cite this paper: Singh, R., Mishra, S.R.., Sushobhana, Passey, J., Kumar, P., Singh, S., Sinha, P. and Gupta, S. (2015) Sexual Dimorphism in Adult Human Mandible of North Indian Origin. Forensic Medicine and Anatomy Research, 3, 82-88. 


\section{Introduction}

Identification and sex determination of human skeletal remains are a critical problem in a forensic study. Bones are an important tool for determining the age, sex and stature of an individual and thus assist in establishing the identity in a medicolegal case. Nevertheless such osteometric studies help in establishing the process of evolution, race and demographic profile. By sex determination, the job of identification is reduced to half. If the gender of human skeletal remains is assessed correctly, then further investigations are likely to be more accurate as separate male and female standards may be then used for estimations of both age and stature. It is widely accepted that the pelvis exhibits the greatest sexual dimorphism [1]. However, a perfect pelvis is not present in most circumstances with incomplete pelvis, and a mandible of the skull becomes an important source for sex confirmation. As a component of the skull, the mandible may be considered as second most sexually dimorphic bone [2]. The mandible is the most durable facial bone that retains its shape better than other [3] [4]. In mass disasters it can retain its shape better than other and commonly resist post mortem damages and form an important source of information about sexual dimorphism [5].

The mandible has a horizontally curved body that is convex forwards, and two broad rami bear the coronoid and condyloid processes. Normally morphological and metric methods are used to determine the sex of a mandible. Male and female mandibles are distinguished by general size [6], chin shape [3] [8], gonial angle [7] [8] or flare [2] [3] and muscular markings [7] [9] [10]. In general, the male mandibles are large, slightly more robust with prominent muscular attachment sites than the female mandibles. The present study is conducted to assess the sexual dimorphism in the few metric and morphological parameters in determination of the sex of dry adult human mandibles of Indian origin.

\section{Material and Methods}

The study was done on 50 adult dry, complete, undamaged human mandibles of North Indian origin, available in the Anthropology Museum of Department of Anatomy of G. S. V. M. Medical College, Kanpur. The sex of the respective skull was known and the study was envisaged to confirm the sexual dimorphism in the mandible. The plan of the study was as follows:

A) In the first step of study, based on morphological features mandibles were categorized into male and female, taking into account the following three morphological features:

- shape of the angle of symphysis menti: square/rounded;

- gonial flare: inverted/everted;

- muscular markings: less prominent/more prominent.

The findings \& sex so determined was recorded.

B) The sex as predetermined on the basis of skull was taken into account and accordingly mandibles were divided in two groups Males $(n=29)$ \& Females $(n=21)$. Now the metric parameters were measured with a Stainless Steel Vernier Calliper of $0.1 \mathrm{~mm}$ precision. The Parameters used in the present study were:

BICONDYLAR BREADTH-the Straight distance between the most lateral points on the two condyles (Figure 1);

BIGONIAL BREADTH-the Straight distance between the two gonia (Figure 2).

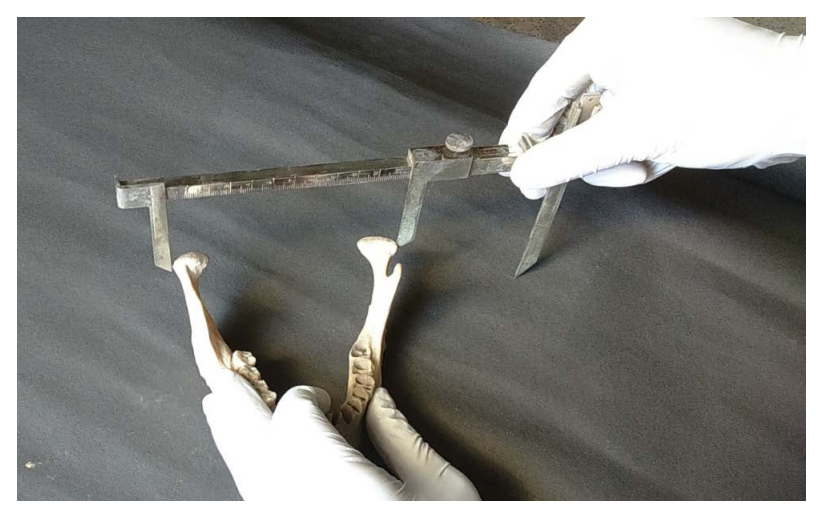

Figure 1. Bicondylar breadth measured with Vernier Calliper. 


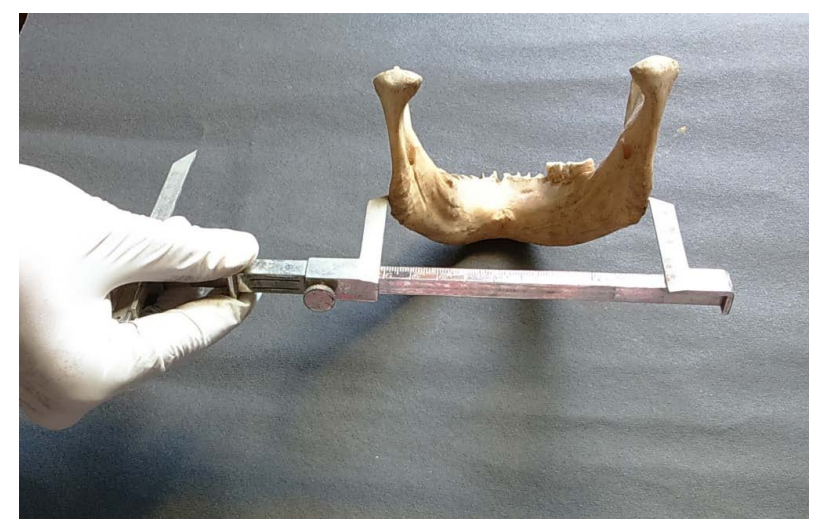

Figure 2. Bigonial breadth measured with Vernier Calliper.

C) Data management and statistical analysis.

After all the measurements were done, observations in the male and female bones were statistically analyzed. Student " $t$ " test was performed. Mean and standard deviation were calculated for the ranges of each parameter of both the genders. P value was determined to assess the significance of the observations.

\section{Result}

The results of the study were as follows:

On the basis of the morphological parameters 18 of the mandibles were categorized as male while 32 as females. In the females the shape of symphysis menti was round, the gonion flare was inverted and the muscular markings were smooth or less prominent. In males the shape of symphysis menti was square, the gonion flare was everted and the muscular markings were more prominent (Table 1).

As per the predetermined sex of the related skulls, there were 21 females and 29 males. This was taken as standard and mandibles were classified in two groups-females (21) and males (29). Metric parameters were measured in both groups.

In the present study the bicondylar breadth was $10.17 \pm 0.58 \mathrm{~cm}$ in females and $11.22 \pm 0.68 \mathrm{~cm}$ in males. Student $t$ test was done for the two sets of mean values. $P$ value was $<0.0001$ and indicated that the results were statistically extremely significant (Table 2).

In the present study the bigonial breadth was $8.43 \pm 0.47 \mathrm{~cm}$ in females and $9.62 \mathrm{~cm} \pm 0.72 \mathrm{~cm}$ in males. Student $t$ test was done for the two sets of Mean values. P value was $<0.0001$ and indicated that the results were statistically extremely significant (Table 3).

\section{Discussion}

The skull is the second most sexually dimorphic region of the human skeleton apart from pelvis. As a component of the skull, the mandible may also be considered sexually dimorphic [2]. So the study was carried out to assess the sexual dimorphism in mandible. The sex predetermined on the basis of the skull was taken as standard and accordingly 21 female and 29 male mandibles were taken in the present study.

In general male mandibles are large, prominent muscular attachment sites and slightly more robust than the female mandibles. The outer appearance of male mandibles is usually irregular, whereas that of females is likely to be even. Several non-metric traits of the mandible have been associated with sex. This contradiction may be caused by relative development of the musculoskeletal system in different sexes. Therefore, mandibular size and shape is affected by variable lifestyles, dietary behaviour, and also racial groups [2] [11]. In addition, developmental stages and growth rates of male and female mandibles are different. Since males reach puberty later than females, the growth of their mandibles and skulls seems to extend beyond that of maturing females [7]. The sexual dimorphisms observed can also arise due the difference in the levels of testosterone between males and females, because testosterone brings about a direct increase in the size and mass of muscles and bones, and thus changes in the shape of the face [12].

In the present study sexual dimorphism was seen in the morphology of mandible. Sex so determined was 18 females and 32 males. Mandibles in males were found to have square symphysis menti, everted gonial flare 
Table 1. Observations done on the basis of morphological parameters.

\begin{tabular}{ccc}
\hline Features & \multicolumn{2}{c}{ No. Of Mandibles $=50$} \\
\hline Symphysis menti & Square, U-shaped & Rounded \\
Gonial flaring & Everted & Inverted \\
Muscular markings & Prominent & Not prominent \\
No. of Bones & 32 & 18 \\
Sex Determined & Male & Female \\
\hline
\end{tabular}

Table 2. Bicondylar breadth measured in 50 mandibles of North Indian origin.

\begin{tabular}{ccc}
\hline Measurements & Female & Male \\
\hline No. of Bones & 21 & 29 \\
Range (cm) & $8.4-10.7$ & $10.6-12.2$ \\
Mean (cm) & 10.17 & 11.22 \\
Standard Deviation & 0.58 & 0.68 \\
95\% Confidence Interval & $9.90-10.43$ & $10.96-11.48$ \\
\hline
\end{tabular}

Table 3. Bigonial breadth measured in 50 mandibles of North Indian origin.

\begin{tabular}{ccc}
\hline Measurements & Female & Male \\
\hline No. Of Bones & 21 & 29 \\
Range (cm) & $7.3-8.9$ & $8.9-10.4$ \\
Mean (cm) & 8.43 & 9.62 \\
Standard Deviation & 0.47 & 0.72 \\
95\% Confidence Interval & 8.22 to 8.64 & $9.34-9.89$ \\
\hline
\end{tabular}

and prominent muscular markings where as in females the angle of symphysis menti was rounded in shape, inverted gonial flare and less prominent muscular markings. Gonial flaring [11], a broad ascending ramus, high symphysis and small mental eminence [13] [14] and squarish symphysis menti. [15] have been marked as male features in past studies. However, the sex determined according to the morphological feature was erroneous in 3 mandibles (6 percent) which appeared to be male instead of female.

Studies done on the nonmetric examination on South African sub adult samples claimed that, shape differences in the symphyseal region and anterior body of the mandible can be used to predict sex with above $80 \%$ accuracy [16]. The most accurate single indicators among cranial methods were the robustness of the mandible with accuracy of $70.93 \%$ [17].

The mandible has been extensively studied on the basis of biometric study [18], mathematical methods [19], parameters like symphyseal height, gonial angle, bigonial breadth etc. [2] [20]. Many variables showed significant differences which includes: bicondylar breadth, gonial angle and minimum ramus breadth [21].

In the present study, the bicondylar breadth in female is $10.17 \pm 0.58$ and in male is $11.22 \mathrm{~cm} \pm 0.68$. Student $\mathrm{t}$ test was done for the two sets of Mean value. $\mathrm{P}$ value was $<0.0001$ and the results were highly significant. The results are similar to as reported in past [22]-[26] (Table 4). In a study on 207 mandibles in south Indian Population the bicondylar breadth of mandible was $11.26 \mathrm{~cm}$ and for females was $10.77 \mathrm{~cm}$. Standard deviation was 0.53 in males and 0.53 in females [22]. Similar values were recorded by past workers as well [23]-[26]. References for the study of mandibles in North Indian Population were not available.

In the present study the bigonial breadth in female is $8.43 \pm 0.47$ and in male is $9.62 \mathrm{~cm} \pm 0.72$. Student $t$ test was done for the two sets of mean value. P value was $<0.0001$ and the results were highly significant. The results are similar to as reported in past [22]-[26] (Table 5). In a study on 207 mandibles in south Indian Popula- 
Table 4. Comparison of the data of Bicondylar breadth measured in present study with other studies.

\begin{tabular}{ccc}
\hline Authors & Female $($ Mean $(\mathrm{cm}) \pm \mathrm{SD})$ & Male $($ Mean $(\mathrm{cm}) \pm \mathrm{SD})$ \\
\hline Jayakaran et al. (2000) & $10.77 \pm 0.53$ & $11.26 \pm 0.53$ \\
Franklin et al. (2007) & $10.86 \pm 0.58$ & $11.36 \pm 0.60$ \\
Ranganath et al. (2008) & $11.51 \pm 0.93$ & $10.98 \pm 1.48$ \\
Ongkana et al. (2009) & $11.61 \pm 0.59$ & $12.38 \pm 0.63$ \\
Vinay et al. (2013) & $10.82 \pm 0.70$ & $11.34 \pm 0.55$ \\
Present Study & $10.17 \pm 0.58$ & $11.22 \pm 0.68$. \\
\hline
\end{tabular}

Ref. [22]-[26].

Table5. Comparison of the data of Bigonial breadth measured in present study with other studies.

\begin{tabular}{ccc}
\hline Authors & Female $($ Mean $(\mathrm{cm}) \pm$ SD) & Male $($ Mean $(\mathrm{cm}) \pm \mathrm{SD})$ \\
\hline Jayakaran et al. $(2000)$ & $8.71( \pm 0.48)$ & $9.38( \pm 0.54)$ \\
Franklin et al. $(2007)$ & $8.70( \pm 0.56)$ & $9.35( \pm 0.57)$ \\
Ranganath et al. (2008) & $8.62( \pm 0.72)$ & $8.68( \pm 1.37)$ \\
Ongkana et al. (2009) & $8.97( \pm 0.59)$ & $9.68( \pm 0.77)$ \\
Vinay et al. (2013) & $8.74 \pm 0.54$ & $9.45 \mathrm{~cm} \pm 0.53$ \\
Present Study & $8.43 \pm 0.47$ & $9.62 \pm 0.72$. \\
\hline
\end{tabular}

Ref. [22]-[26].

tion the bigonial bradth was $8.71 \mathrm{~cm}$ in females and $9.38 \mathrm{~cm}$ in males [22]. Similar values were found by past workers as well [23]-[26]. References for the study of mandibles in North Indian Population were not available. Some of the difference can be attributed to the difference in the population and the races studied viz. South Indian [22] [24] [26], South African [23], Thai origin [25] (Table 5).

In the statistical analysis of the observations it was seen that the difference in the values of male and female mandible were statistically very significant indicating that mandible expresses strong sexual dimorphism. It is vividly reflected that the bicondylar breadth and bigonial breadth exhibit sexual dimorphism. The morphological parameters chosen in the study also demonstrate sexual dimorphism but need more expertise.

Its noteworthy that as the metric parameters chosen for the study appear to be size dependant and may represent the proxy parameters of the corporal size there are chances of some errors in the cases of small males and large females. In such cases other size independent metric parameters and other skeletal bones should be taken in account. As a future scope of the study size dependence of the bigonial breadth, bicondylar breadth and other metric parameters on mandible with cranial size or femoral length should be studied.

However it can be concluded that all the three parameters chosen in the study exhibit statistically significant sexual dimorphism.

\section{Conclusion}

In present study, 21 female \& 29 male mandibles are taken and the results conclude that both metric \& non-metric parameters exhibit sexual dimorphism. It can be concluded from the present study that one or two metric parameters are not sufficient to determine the exact sex of adult human mandible, but rather requires more metric parameters along with morphological parameters. Though both metric parameters are probably size-dependent, and therefore always tend to misclassify small males and big females. Yet mandible is a reliable tool for determination of sex and can be of great help when few other bones are also available.

\section{Conflict of Interest}

None. 


\section{Acknowledgements}

We are thankful to the caretakers of the Anthropology museum, Department of Anatomy, GSVM Medical College, Kanpur. The work was not funded by any agency.

\section{References}

[1] Scheuer, L. (2002) Application of Osteology to Forensic Medicine. Clinical Anatomy, 15, 297-312. http://dx.doi.org/10.1002/ca.10028

[2] Giles, E. (1964) Sex Determination by Discriminate Function Analysis of the Mandible. American Journal of Physical Anthropology, 22, 129-135.

[3] Hu, K.-S., Koh, K.-S., Han, S.-H., Shin, K.-J. and Kim, H.-J. (2006) Sex Determination Using Nonmetric Characteristics of the Mandible in Koreans. Journal of Forensic Sciences, 51, 1376-1382. http://dx.doi.org/10.1111/j.1556-4029.2006.00270.x

[4] Balci, Y., Yavuz, M.F. and Cağdir, S. (2005) Predictive Accuracy of Sexing the Mandible by Ramus Flexure. HOMO-Journal of Comparative Human Biology, 55, 229-237. http://dx.doi.org/10.1016/j.jchb.2004.07.006

[5] Kim, H.J., Lee, H.Y., Chung, I.H., Cha, I.H. and Yi, CK. (1997) Mandibular Anatomy Related to Sagittal Split Ramus Osteotomy in Koreans. Yonsei Medical Journal, 38, 19-25. http://dx.doi.org/10.3349/ymj.1997.38.1.19

[6] Ongkana, N. and Sudwan, P. (2009) Gender Difference in Thai Mandibles Using Metric Analysis. Chiang Mai Medical Journal, 48, 43-48.

[7] Aitchison, J. (1963) Sex Differences in Teeth, Jaws, and Skulls. Dental Practice, 15, 52-57.

[8] Ongkana, N. and Sudwan, P. (2010) Morphologic Indicators of Sex in Thai Mandibles. Chiang Mai Medical Journal, 49, $123-128$.

[9] Shamout, A.R., Ammoush, M., Alrbata, R. and Habahbah, A.A. (2012) Age and Gender Differences in Gonial Angle, Ramus Height and Bigonial Width in Dentate Subjects. Pakistan Oral \& Dental Journal, 32, 81-87.

[10] Baydaş, B., Yavuz, I., Dağsuyu, I.M., Bölükbaşi, B. and Ceylan, I. (2004) An Investigation of Maxillary and Mandibular Morphology in Different Overjet Groups. Australian Orthodontic Journal, 20, 11-18.

[11] Devi, R., Arna, N., Manjunath, K.Y. and Balasubramanyam, M. (2003) Incidence of Morphological Variants of Mandibular Lingula. Indian Journal of Dental Research, 14, 210-213.

[12] Osunwoke, E.A., Amah-Tariah, F.S., Obia, O., Ekere, I.M. and Ede, O. (2011) Sexual Dimorphism in Facial Dimensions of the Bini's of South-Southern Nigeria. Asian Journal of Medical Sciences, 3, 71-73.

http://www.maxwellsci.com/print/ajms/v3-71-73.pdf

[13] Krogman, W.M. and Iscan, M.Y. (1986) The Human Skeleton in Forensic Medicine. 2nd Edition, Charles C. Thomas, Springfield.

[14] Schwartz, J.H. (1995) Skeleton Keyes: An Introduction to Human Skeletal Morphology Development and Analysis. Oxford University Press, New York.

[15] Heereshchandra and Malaviya, G. (1972) The Sexing of Human Mandible. Journal of the Indian Academy of Forensic Sciences, II, 7.

[16] Loth, S.R. and Henneberg, M. (1998) Mandibular Ramus Flexure Is a Good Indicator of Sexual Dimorphism. American Journal of Physical Anthropology, 105, 91-92. http://dx.doi.org/10.1002/(SICI)1096-8644(199801)105:1<91::AID-AJPA9>3.0.CO;2-G

[17] Indrayana, N.S., Glinka, J. and Mieke, S. (1998) Mandibular Ramus Flexure in an Indonesian Population. American Journal of Physical Anthropology, 105, 89-90. http://dx.doi.org/10.1002/(SICI)1096-8644(199801)105:1<89::AID-AJPA8>3.0.CO;2-8

[18] Morant, G.M., Collett, M. and Adyanthaya, N.K. (1936) A Biometric Study of the Human Mandible. Biometrics, 28, 84-122.

[19] Martin, E.S. (1936) A Study of an Egyptian Series of Mandibles with Special Reference to Mathematical Methods of Sexing. Biometrica, 28, 119-178. http://dx.doi.org/10.1093/biomet/28.1-2.149

[20] Hanihara, K. (1959) Sex Diagnosis of Japanese Skulls and Scapulae, by Means of Discriminant Function. Journal of Anthropological Society of Nippon, 67, 191-197.

[21] Kharoshah, M.A., Al Madani, O.M., Galeb, S.S., Zaki, M.K. and Fattah, Y.A. (2010) Sexual Dimorphism of the Mandible in a Modern Egyptian Population. Journal of Forensic and Legal Medicine, 17, 213-215.

[22] Jayakaran, F., Rajangam, S., Janakiram, S. and Thomas, I.M. (2000) Sexing of the Mandible. Anatomica Karnataka, 1, $11-16$. 
[23] Franklin, D., O’Higgins, P. and Oxnard, C.E. (2008) Discriminant Function Sexing of the Mandible of Indigenous South Africans. Forensic Science International, 179, 84-85. http://dx.doi.org/10.1016/j.forsciint.2008.03.014

[24] Ranganath, V., Yogitha, R. and Roopa, R. (2008) Sexual Dimorphism in Mandibular Morphology: A Study on South Indian Sample. South Asian Anthropologist, 8, 9-11.

[25] Ongkana, N. and Sudwan, P. (2009) Gender Differences in Thai Mandibles Using Metric Analysis. Chiang Mai Medical Journal, 48, 43-48.

[26] Vinay, G., Gowri, S.R.M. and Anbalagan, J. (2013) Sex Determination of Human Mandible Using Metrical Parameters. Journal of Clinical and Diagnostic Research, 7, 2671-2673. 